\title{
Anthropometric measurements in childhood and prediction of cardiovascular risk factors in adulthood: Kaunas cardiovascular risk cohort study
}

\author{
Janina Petkeviciene ${ }^{1 *}$, Jurate Klumbiene ${ }^{1}$, Vilma Kriaucioniene ${ }^{1}$, Asta Raskiliene ${ }^{1}$, Edita Sakyte ${ }^{1}$
} and Indre Ceponiene ${ }^{2}$

\begin{abstract}
Background: This study aimed to examine the associations between anthropometric measurements in childhood and adulthood as well as the effect of childhood body mass index (BMI) and skinfold thickness in the prediction of adult cardiovascular risk factors.

Methods: The Study subjects were participants of the Kaunas Cardiovascular Risk Cohort study. They were 12-13 years old at the time of the baseline survey (1977) and 48-49 years old in the 35-year follow-up survey $(2012, n=506)$. In childhood, height, weight, subscapular and triceps skinfold thickness measurements were taken. In 2012, health examination involved measurements of blood pressure (BP), BMI, waist circumference, glucose, lipids, and high-sensitivity C-reactive protein (CRP) levels. Logistic regression models were fitted to assess the associations of childhood BMI and skinfold thicknesses as well as BMI gain with cardiovascular risk factors in middle age. All logistic regression models were adjusted for sex, physical activity level, alcohol consumption, smoking and family history of obesity.
\end{abstract}

Results: Over 35 years of follow-up, BMl gain was greater in men than in women. Anthropometric measurements in childhood significantly correlated with values measured in adulthood. The highest correlation coefficients were defined for weight and BMI measurements (in girls $r=0.56$ and $r=0.51$ respectively; in boys $r=0.45$ and $r=0.41$ respectively, $\mathrm{P}<0.001)$. Mean values of change in BMI were similar in all quintiles of childhood BMl; however, prevalence of adult obesity increased considerably with increasing quintiles. The risk of adult obesity, metabolic syndrome, hyperglycaemia or type 2 diabetes, and elevated level of high-sensitivity CRP increased with a rise in childhood BMI and skinfold thicknesses, irrespectively of BMI gain from childhood to adulthood. No relationship was found between childhood anthropometric measurements and arterial hypertension, raised level of triglycerides or reduced level of HDL cholesterol. Gain in BMI from childhood to adulthood was associated with increased odds of all above-mentioned risk factors independently of childhood BMI.

Conclusions: Risk of metabolic syndrome, hyperglycaemia and diabetes, and elevated high-sensitivity CRP may be affected by childhood BMI and skinfold thickness, while risk of hypertension, raised triglycerides and reduced HDL cholesterol is associated more strongly with BMI gain from childhood to adulthood.

Keywords: Body mass index, Skinfold thickness, Cardiovascular risk factors, Longitudinal cohort study

\footnotetext{
* Correspondence: janina.petkeviciene@|smuni.lt

${ }^{1}$ Faculty of Public Health, Medical Academy, Lithuanian University of Health

Sciences, Siaures av. 57, Kaunas, Lithuania

Full list of author information is available at the end of the article
} 


\section{Background}

The growing prevalence of overweight and obesity in children is a serious public health concern. Worldwide, proportion of overweight and obese children rose by 47.1\% between 1980 and 2013 [1]. In 2013, 23.8\% of boys and $22.6 \%$ of girls were overweight or obese in developed countries. In Lithuania, the proportion of overweight boys (13\%) and overweight girls (8\%) aged 13 years was one of the lowest among all 39 countries, participating in Health Behaviour in School-aged Children study (2009/2010) [2]. However, recent studies provided evidence that prevalence of overweight is increasing in the country, particularly among primary-school children [3].

Overweight children are known to be more likely to become obese adults than children with normal weight [4-7]. There is substantial evidence that obesity in adulthood is strongly related to cardiovascular risk $[8,9]$. Data of prospective studies showed that each increase of $5 \mathrm{~kg} / \mathrm{m}^{2}$ in body mass index (BMI) was associated with $40 \%$ higher cardiovascular mortality [9]. This association is explained by the adverse cardiovascular risk profile in obese individuals characterized by high blood pressure (BP), dyslipidaemia, hyperglycaemia, elevated level of $\mathrm{C}$-reactive protein (CRP) and higher level of other biomarkers of cardiovascular risk [10,11]. However, the contribution of childhood obesity to cardiovascular risk in adulthood is not clearly defined. A meta-analysis of prospective studies showed that for children 7 to 18 years old a $1 \mathrm{~kg} / \mathrm{m}^{2}$ increase in BMI was associated with a $5 \%$ increase in the risk of coronary heart disease (CHD) in adults [12]. Nevertheless, there was a considerable statistical heterogeneity in the relative risk of outcome between studies. In a systematic review, Lloyd et al. found little evidence to suggest that childhood obesity is an independent cardiovascular risk factor [13]. Several studies demonstrated that prediction of cardiovascular risk depended on obesity pattern. Permanent obesity through childhood to adulthood had greater effect on cardiovascular risk than adult obesity only $[14,15]$. In contrast, obese children who became non-obese by adulthood had the same risk of outcomes as individuals who never experienced obesity [14]. It is still unclear whether the observed associations between childhood obesity and adult cardiovascular risk reflect the tracking of BMI from childhood to adulthood or whether childhood adiposity has an independent effect on risk of adverse health outcomes, irrespectively of the degree of adult adiposity.

From a public health perspective, early prevention of cardiovascular diseases (CVD) should be given high priority in Lithuania, a post-communist transition country with a very high mortality from CVD and a growing prevalence of overweight in children [16]. For early prevention, it is important to know the links between childhood health indicators and CVD risk in adulthood.
In the current study, the associations between anthropometric measurements in childhood and adulthood as well as the effect of childhood BMI and skinfold thickness in the prediction of adult cardiovascular risk factors were examined using the data from Kaunas (Lithuania) 35-year follow-up cohort study.

\section{Methods}

\section{Study design and sample}

The Kaunas Cardiovascular Risk Cohort study was initiated in 1977, when a random sample of Kaunas schoolchildren born in 1964 $(\mathrm{n}=1082)$ was examined within the framework of the International Study of Juvenile Hypertension [17]. Fifteen secondary schools of Kaunas city were randomly selected to participate in the study. In each school all 6th year schoolchildren were examined. In 2012, a follow-up survey of the cohort was carried-out. Over 35-year period, 91 individuals (8.4\%) died, 103 subjects (9.5\%) emigrated from Lithuania, $4(0.4 \%)$ individuals were seriously ill, and the addresses of $90(8.3 \%)$ subjects were not available in the National Population Register; therefore, the eligible sample consisted of 794 subjects. A total of 507 subjects $(63.9 \%$ of eligible sample), aged 48-49 years, participated in the last follow-up survey. For one disabled subject (sitting in a wheelchair) not all anthropometric measurements were taken; therefore he was excluded from the analysis.

The study protocol was approved by the Lithuanian Bioethics Committee. Written consent on behalf of the children enrolled in the first survey (1977) was obtained from parents or guardians. Written informed consent for the participation in the follow-up survey (2012) was obtained from all participants.

\section{Measurements in childhood}

Anthropometric measurements were obtained by trained examiners according to a standardized protocol. The height of participants, without shoes, was measured to the nearest centimetre with a stadiometer. The body weight of participants, wearing light indoor clothing and no shoes, was measured to the nearest $0.1 \mathrm{~kg}$ with standardized medical scales. BMI was calculated as weight divided by height squared $\left(\mathrm{kg} / \mathrm{m}^{2}\right)$. In childhood, overweight and obesity were defined using age and sex specific cut-off points for BMI recommended by the International Obesity Task Force (IOTF) [18].

The triceps and subscapular skinfold thicknesses were measured two times to the nearest $1.0 \mathrm{~mm}$ with a Harpenden calliper and the mean values were used in the analyses. The triceps skinfold was taken on the midline of the posterior surface of the arm (over the triceps muscle) at the level of the mid-point between the acromiale and the radiale. The subscapular skinfold was measured just below the angle of the scapula. The sum 
of the triceps and subscapular skinfold thicknesses was used in the logistic regression analysis.

BP was measured from the right brachial artery with a standard mercury sphygmomanometer in the sitting position after 5 minutes of rest. BP measurements were performed to the nearest $2 \mathrm{mmHg}$. The first Korotkoff phase was used to determine systolic BP, and the fifth phase was used to determine diastolic BP. Three consecutive BP measurements were taken. The average of these three measurements was used in the analysis.

\section{Measurements in adulthood}

Height and weight were measured following the same methodology as in childhood. Overweight in adulthood was defined as BMI of $25-29.9 \mathrm{~kg} / \mathrm{m}^{2}$, and obesity as BMI equal to or higher than $30 \mathrm{~kg} / \mathrm{m}^{2}$.

Waist circumference was measured at the mid-point between the lower margin of the last palpable rib and the top of the iliac crest using a stretch-resistant tape, to the nearest $0.5 \mathrm{~cm}$.

BP measurements were obtained following the same methodology as in childhood. Hypertension in adulthood was defined as systolic $\mathrm{BP} \geq 140 \mathrm{mmHg}$ and/or diastolic $\mathrm{BP} \geq 90 \mathrm{mmHg}$ or $\mathrm{BP}<140 / 90 \mathrm{mmHg}$ using antihypertensive medication for the last two weeks before examination.

Blood samples for lipids, glucose, and high-sensitivity CRP measurements were taken in the morning after fasting at least 12 hours. All measurements were performed in a certified laboratory on an automatic analyser Cobas Integra 400 plus. Serum lipid and glucose levels were determined using conventional enzymatic methods. Hexokinase was used for measurement of glucose level. High-sensitivity CRP level was assessed using immunoturbidimetric method.

Metabolic syndrome was determined according to criteria of International Diabetes Federation: central obesity defined as waist circumference $\geq 94 \mathrm{~cm}$ for men and $\geq 80 \mathrm{~cm}$ for women plus any two of the following four factors: raised triglycerides level $(\geq 1.7 \mathrm{mmol} / \mathrm{L})$; reduced high-density lipoprotein (HDL) cholesterol level (for men $<1.03 \mathrm{mmol} / \mathrm{L}$ and for women $<1.29 \mathrm{mmol} / \mathrm{L}$ ); raised blood pressure (systolic $\mathrm{BP} \geq 130 \mathrm{~mm} \mathrm{Hg}$ or diastolic $\mathrm{BP} \geq 85 \mathrm{~mm} \mathrm{Hg}$, or treatment of previously diagnosed hypertension); raised fasting plasma glucose ( $\geq 5.6 \mathrm{mmol} / \mathrm{L}$ or previously diagnosed type 2 diabetes) [19]. Participants were classified as having type 2 diabetes mellitus if they had received a diagnosis from a physician and reported the use of glucose-lowering medication. Type 2 diabetes was diagnosed only for 15 individuals; therefore, this outcome was analysed together with hyperglycaemia.

Dyslipidaemias and hyperglycaemia were defined using the same criteria as for metabolic syndrome. The data on the use of lipid lowering medications were collected. Only 37 participants (7.3\%) used such medications. All of them had elevated levels of total and LDL cholesterol at the time of health examination; therefore they were included in the group of participants having hypercholesterolaemia or high level of LDL cholesterol. Highsensitivity CRP level equal to or higher than $3 \mathrm{mg} / \mathrm{L}$ was considered as elevated [20].

A standard questionnaire was applied to obtain data on alcohol consumption. The questionnaire contained questions about type and frequency of alcohol consumption and amount of alcohol consumed at one occasion. The amount of alcohol consumed at one occasion was recalculated into standard alcohol units (SAUs) using the following formula: SAUs $=$ amount (in litres) $\times$ strength of alcoholic drink (beer - 5\%, wine - $12 \%$, strong alcohol - 40\%). One SAU equals to $10 \mathrm{~g}$ of ethanol. The amount of SAUs consumed during a month was calculated. Risky alcohol consumption was defined as drinking of 56 SAUs or more per month for men and drinking of 28 SAUS or more per month for women. Information on cigarette smoking was collected using a standard questionnaire. The questionnaire contained questions about frequency and intensity of smoking. Participants were divided in daily smokers and others. Physical activity was assessed using the International Physical Activity Questionnaire (IPAQ) [21]. Physical activity of less than $600 \mathrm{MET}$-min/week was considered as low. Family history of obesity was defined as positive if a participant reported that at least one of the parents, brothers or sisters was obese.

\section{Statistical analysis}

Categorical variables were expressed as percentages and tested by the $\chi^{2}$ test. The normality of distribution of continuous variables was tested by Kolmogorov-Smirnov test. Means and standard deviations (SD) were presented for the normally distributed continuous variables while median and interquartile range were calculated for the distributions that did not meet the criteria of normality. Student $t$ test and analysis of variance were used to compare the mean values of normally distributed variables and Mann-Whitney test was applied for the comparison of non-normal distributions. Spearman correlation coefficients were calculated to determine the associations between anthropometric measurements in childhood and adulthood. Mean BMI gain from childhood to adulthood and adult obesity prevalence were calculated in quintiles of childhood BMI.

Logistic regression analysis was performed to determine the associations of childhood BMI and the sum of the skinfold thicknesses with adult cardiovascular risk factors without and with adjustment for the change in BMI from childhood to adulthood. A separate logistic 
regression model was calculated for every risk factor. All logistic regression models were adjusted for sex, physical activity level, alcohol consumption, smoking and family history of obesity. Modification of the main effect of childhood BMI by sex was assessed by the inclusion of the interaction term in all models. Interaction terms were not statistically significant $(p>0.05)$, therefore the results were presented for both genders. All statistical analyses were performed using statistical software package SPSS version 20.0 for Windows. P values of less than 0.05 were considered to be statistically significant.

\section{Results}

The baseline characteristics in childhood, including anthropometric measurements, were compared between those who participated $(n=506)$ and those who did not participate $(n=576)$ in the 2012 follow-up survey. No statistically significant differences of analysed variables were found between the groups (data are not shown).

The characteristics of the study participants in the first survey (1977) and in the last survey (2012) are presented in Table 1. In childhood, the mean values of all anthropometric measurements of girls were higher compared with boys. Despite this fact, no sex differences in the prevalence of overweight and obesity defined using IOTF age- and sex-specific criteria were observed. Almost every tenth child (11.3\% of boys and $12.7 \%$ of girls) was overweight or obese. Over 35 years of follow-up, an increase in height and weight, also BMI gain was greater in men than in women. In adulthood, the prevalence of overweight reached $43.9 \%$ in men and $35.0 \%$ in women $(\mathrm{P}=0.01)$. Proportion of obese men and women $(25.2 \%$ and $21.4 \%$, respectively) did not differ significantly. The mean value of waist circumference was higher in adult men than in women.

Prevalence of CVD risk factors was high in the cohort (Table 1). Proportion of adult men having hypertension, metabolic syndrome, hyperglycaemia or type 2 diabetes and raised level of triglycerides was higher than that of women. Risky alcohol consumption and smoking were also more common among men.

Weight, BMI and the skinfold thicknesses in childhood significantly correlated with adult anthropometric measurements (Table 2). The Spearman correlation coefficients were slightly higher in women than in men; however, few differed significantly. The highest correlation coefficients were defined for weight and BMI measurements in childhood and adulthood (in girls $\mathrm{r}=0.56$ and $r=0.51$ respectively; in boys $r=0.45$ and $r=0.41$ respectively, $\mathrm{P}<0.001$ ).

BMI gain from childhood to adulthood did not depend on the initial BMI level (Table 3). Namely, mean values of change in BMI were similar in all quintiles of childhood BMI. However, prevalence of adult obesity increased
Table 1 Characteristics of the study population in childhood and adulthood

\begin{tabular}{|c|c|c|c|}
\hline Characteristic & $\begin{array}{l}\text { Men } \\
\mathrm{n}=\mathbf{2 3 0}\end{array}$ & $\begin{array}{l}\text { Women } \\
\mathrm{n}=\mathbf{2 7 6}\end{array}$ & $P$ value \\
\hline \multicolumn{4}{|l|}{ Childhood (12-13 years) } \\
\hline Height, $\mathrm{cm}^{*}$ & $155.2(7.8)$ & $158.4(6.9)$ & $<0.001$ \\
\hline Weight, kg** & $42.9(13.2)$ & $47.1(13.0)$ & $<0.001$ \\
\hline $\mathrm{BMI}, \mathrm{kg} / \mathrm{m}^{2 * *}$ & $17.8(3.4)$ & $18.6(3.3)$ & 0.003 \\
\hline Triceps skinfold thickness, mm** & $10.2(5.1)$ & $13.7(6.4)$ & $<0.001$ \\
\hline Subscapular skinfold thickness, mm* & $5.5(2.4)$ & $7.3(3.8)$ & $<0.001$ \\
\hline Overweight/obesity prevalence, $\%$ & 11.3 & 12.7 & 0.623 \\
\hline Obesity prevalence, $\%$ & 1.7 & 2.5 & 0.528 \\
\hline \multicolumn{4}{|l|}{ Adulthood (48-49 years) } \\
\hline Height, $\mathrm{cm}^{*}$ & $179.3(6.3)$ & $167.1(6.0)$ & $<0.001$ \\
\hline Weight, kg** & $86.5(20.0)$ & $70.4(20.1)$ & $<0.001$ \\
\hline BMI, $\mathrm{kg} / \mathrm{m}^{2 * *}$ & $26.9(5.6)$ & $25.6(6.6)$ & 0.008 \\
\hline Waist circumference, $\mathrm{cm}^{*}$ & $97.2(12.5)$ & $85.0(13.5)$ & $<0.001$ \\
\hline Overweight prevalence, \% & 43.9 & 35.0 & 0.01 \\
\hline Obesity prevalence, $\%$ & 25.2 & 21.4 & 0.341 \\
\hline $\begin{array}{l}\text { Change in BMl from childhood to } \\
\text { adulthood, } \mathrm{kg} / \mathrm{m}^{2 *}\end{array}$ & $9.1(4.6)$ & $7.6(4.4)$ & $<0.001$ \\
\hline Hypertension, \% & 60.2 & 30.8 & $<0.001$ \\
\hline Metabolic syndrome, \% & 33.6 & 18.5 & $<0.001$ \\
\hline Hyperglycemia or diabetes, \% & 30.3 & 13.4 & $<0.001$ \\
\hline Raised triglycerides, $\%$ & 34.2 & 14.5 & $<0.001$ \\
\hline Reduced HDL cholesterol, \% & 11.7 & 9.1 & 0.379 \\
\hline Elevated high-sensitivity CRP, \% & 15.2 & 13.4 & 0.610 \\
\hline Low physical activity, \% & 25.5 & 26.4 & 0.724 \\
\hline Risky alcohol consumption, \% & 22.9 & 5.8 & $<0.001$ \\
\hline Daily smoking, \% & 41.6 & 22.9 & $<0.001$ \\
\hline Family history of obesity, \% & 45.9 & 45.5 & 0.502 \\
\hline
\end{tabular}

*Mean and standard deviation; **median and interquartile range. Abbreviations: $B M I$ body mass index, $H D L$ high density lipoprotein, CRP C-reactive protein.

considerably with increasing quintiles. More than a half of children who had the highest BMI (the $5^{\text {th }}$ quintile) were obese as adults. In addition, children whose BMI belonged to the $4^{\text {th }}$ quintile were also at increased risk of adult obesity. From this group, $31.1 \%$ of boys and $27.3 \%$ of girls became obese by the time of the last survey, as compared to $8.7 \%$ of boys and $9.1 \%$ of girls with BMI from the $1^{\text {st }}$ quintile.

The logistic regression models unadjusted for BMI gain from childhood to adulthood showed that BMI in childhood predicted development of obesity and central obesity in adults (Table 4). Moreover, childhood BMI was predictive for metabolic syndrome, hyperglycaemia or type 2 diabetes and elevated level of high-sensitivity CRP in adulthood. Importantly, these associations remained 
Table 2 The Spearman correlation coefficients between anthropometric measurements in childhood and adulthood

\begin{tabular}{llll}
\hline $\begin{array}{l}\text { Measurements in } \\
\text { childhood }\end{array}$ & \multicolumn{3}{l}{ Measurements in adulthood } \\
\cline { 2 - 4 } Weight & BMI & Waist circumference \\
\hline Men & 0.45 & 0.32 & $0.28^{\text {a }}$ \\
Weight & 0.41 & 0.41 & 0.30 \\
BMl & 0.32 & 0.35 & 0.28 \\
Triceps skinfold & 0.34 & 0.34 & $0.28^{\text {a }}$ \\
Subscapular skinfold & & & \\
Women & & 0.46 & 0.44 \\
Weight & 0.56 & 0.53 & 0.46 \\
BMl & 0.51 & 0.41 & 0.40 \\
Triceps skinfold & 0.40 & 0.47 & 0.44 \\
Subscapular skinfold & 0.44 &
\end{tabular}

All $P$ values $<0.001$.

${ }^{\mathrm{a}}$ statistically significant differences between correlation coefficients of men and women.

Abbreviations: $B M I$ body mass index.

significant after adjustment for BMI gain from childhood to adulthood. No relationship was found between childhood BMI and adult arterial hypertension, raised level of triglycerides or reduced level of HDL cholesterol. Gain in BMI was associated with increased odds of all abovementioned CVD risk factors independently of childhood BMI. Neither childhood BMI, nor gain in BMI were related to total cholesterol and low-density lipoprotein (LDL) cholesterol level (data are not shown).

The skinfold thicknesses in childhood also predicted CVD risk factors in adulthood. The increase in the sum of skinfold thicknesses by 1 standard deviation (SD) was associated with higher odds of obesity and central obesity, metabolic syndrome, hyperglycaemia or type 2 diabetes, and elevated level of high-sensitivity CRP in adulthood (Table 5). The effect of BMI and the skinfold thicknesses on CVD risk factors was not substantially influenced by lifestyle factors (physical activity, alcohol consumption, smoking) and family history of obesity.

\section{Discussion}

Our study has shown that anthropometric measurements in childhood strongly correlated with values measured in adulthood. The risk of adult obesity increased with a rise in childhood BMI and skinfold thickness. Moreover, anthropometric measurements in childhood were associated with the risk of metabolic syndrome, hyperglycaemia or type 2 diabetes, and elevated level of high-sensitivity CRP in adults, irrespectively of BMI gain from childhood to adulthood.

Metabolic risk factors related to cardiovascular health are highly prevalent in Lithuanian population [22]. Such adverse cardiovascular risk profile is a major contributor to high CVD mortality, which is one of the highest in Europe [16]. Our findings suggest that the impact of adiposity on cardiovascular risk begins early in life. Thus the implementation of obesity prevention and control measures in childhood might be one of the strategies for CVD risk reduction in Lithuania.

Previous prospective studies found significant and strong tracking between childhood and adulthood BMI values $[4-7,23]$. In the Young Finns Study, Spearman correlation coefficients for 27-year tracking of BMI of 12 -year-old children were similar to those determined in our cohort ( $\mathrm{r}=0.59$ for men and $\mathrm{r}=0.45$ for women) [7]. Some researchers reported associations between weight status in childhood and adulthood being stronger for girls than for boys $[4,7,23]$. However, opposite findings were also published $[24,25]$. We did not find any substantial gender differences in the associations between anthropometric measurements in childhood and adulthood.

Studies that analysed the risk of becoming overweight by strata of childhood weight revealed that persistence of overweight was greater with increasing childhood BMI $[4,23]$. A systematic review showed that the risk of overweight children to become overweight adults was at

Table 3 Mean values of change in body mass index (BMI) from childhood to adulthood and prevalence of obesity in adulthood by quintiles of BMI in childhood

\begin{tabular}{|c|c|c|c|c|c|c|}
\hline \multirow[t]{3}{*}{ Quintiles of BMI in childhood } & \multicolumn{3}{|l|}{ Men } & \multicolumn{3}{|c|}{ Women } \\
\hline & \multicolumn{2}{|c|}{ Change in BMI } & \multirow{2}{*}{$\begin{array}{l}\text { Obesity prevalence in adulthood } \\
\%\end{array}$} & \multicolumn{2}{|c|}{ Change in BMI } & \multirow{2}{*}{$\begin{array}{l}\text { Obesity prevalence in adulthooc } \\
\%\end{array}$} \\
\hline & Mean & SD & & Mean & SD & \\
\hline $1 s t$ & 9,4 & 3,7 & 8.7 & 7,7 & 4,1 & 9.1 \\
\hline 2nd & 9,1 & 3,7 & 13.0 & 7,5 & 3,1 & 3.6 \\
\hline $3 \mathrm{rd}$ & 9,7 & 5,1 & 23.4 & 6,8 & 3,5 & 10.7 \\
\hline 4th & 9,6 & 3,9 & 31.1 & 8,2 & 5,3 & 27.3 \\
\hline 5 th & 7,5 & 6,0 & 50.0 & 7,8 & 5,4 & 56.4 \\
\hline$P$ value & $0.534^{*}$ & & $<0.001^{* *}$ & $0.128^{*}$ & & $<0.001^{* *}$ \\
\hline
\end{tabular}

*P value from analysis of variance; ${ }^{* *} P$ value from $x^{2}$ test 
Table 4 Odds ratios and $95 \%$ confidence intervals of cardiovascular risk factors in adulthood according to body mass index (BMI) in childhood and change of BMI from childhood to adulthood

\begin{tabular}{|c|c|c|c|c|c|c|}
\hline \multirow[t]{2}{*}{ Risk factor } & \multicolumn{2}{|c|}{ Models with BMI in childhood } & \multicolumn{4}{|c|}{ Models with BMI in childhood and BMI gain } \\
\hline & OR by BMI in childhood & $95 \% \mathrm{Cl}$ & OR by $\mathrm{BMI}$ in childhood & $95 \% \mathrm{Cl}$ & OR by change in BMI & $95 \% \mathrm{Cl}$ \\
\hline Obesity $^{a}$ & 1.38 & $1.27-1.51$ & - & - & - & - \\
\hline Central obesity & 1.23 & $1.14-1.33$ & 2.38 & $1.94-2.91$ & 2.90 & $2.36-3.56$ \\
\hline Metabolic syndrome & 1.12 & $1.05-1.21$ & 1.21 & $1.10-1.32$ & 1.43 & $1.33-1.53$ \\
\hline Hyperglycemia or diabetes & 1.13 & $1.05-1.21$ & 1.15 & $1.06-1.24$ & 1.15 & $1.10-1.22$ \\
\hline Hypertension & 1.02 & $0.95-1.08$ & 1.04 & $0.97-1.12$ & 1.26 & $1.20-1.34$ \\
\hline Raised triglycerides & 0.99 & $0.92-1.07$ & 1.01 & $0.93-1.09$ & 1.22 & $1.15-1.29$ \\
\hline Reduced HDL cholesterol & 1.04 & $0.95-1.14$ & 1.05 & $0.95-1.16$ & 1.20 & $1.13-1.28$ \\
\hline Elevated high-sensitivity CRP & 1.16 & $1.07-1.28$ & 1.19 & $1.09-1.31$ & 1.23 & $1.16-1.30$ \\
\hline
\end{tabular}

Separate logistic regression models were calculated for every risk factor. Odds ratios were calculated for a one-unit increase in the BMI. All logistic regression models were adjusted for sex, physical activity level, alcohol consumption, smoking and family history of obesity.

${ }^{a}$ Because of complete separation, logistic regression was not fitted for calculation of obesity odds when BMI in childhood and BMI gain were included in the model. Significant $(P<0.05)$ values in bold.

Abbreviations: $O R$ odds ratio, $C l$ confidence interval, $B M I$ body mass index, $H D L$ high density lipoprotein, CRP C-reactive protein.

least twice as high as compared with normal-weight children [5]. Moreover, Field et al. demonstrated that children in the upper end of the healthy weight range $\left(50^{\text {th }}\right.$ to $84^{\text {th }}$ percentile) also were at an elevated risk of becoming overweight in adulthood [4]. Similar to this study, our data indicated that almost one third of children with BMI from the $4^{\text {th }}$ quintile became obese as adults. These findings suggest that prevention of adult obesity should be targeted not only at overweight children, but also at children in the upper part of normal weight range, especially in the context of contemporary obesogenic environment.

Table 5 Odds ratios and $95 \%$ confidence intervals of cardiovascular risk factors in adulthood according to the sum of subscapular and triceps skinfold thicknesses in childhood

\begin{tabular}{|c|c|c|c|c|}
\hline \multirow[t]{2}{*}{ Risk factor } & \multicolumn{2}{|c|}{$\begin{array}{l}\text { Models unadjusted } \\
\text { for BMI gain }\end{array}$} & \multicolumn{2}{|c|}{$\begin{array}{l}\text { Models adjusted } \\
\text { for BMI gain }\end{array}$} \\
\hline & OR & $95 \% \mathrm{Cl}$ & OR & $95 \% \mathrm{Cl}$ \\
\hline Obesity & 2.20 & $1.72-2.83$ & 3.10 & $1.20-8.08$ \\
\hline Central obesity & 1.77 & $1.36-2.29$ & 6.14 & $3.84-9.84$ \\
\hline Metabolic syndrome & 1.29 & $1.05-1.60$ & 1.52 & $1.16-2.00$ \\
\hline Hyperglycemia or diabetes & 1.43 & $1.15-1.78$ & 1.52 & $1.21-1.92$ \\
\hline Hypertension & 1.01 & $0.82-1.22$ & 1.06 & $0.85-1.32$ \\
\hline Raised triglycerides & 1.00 & $0.79-1.25$ & 1.03 & $0.80-1.32$ \\
\hline Reduced HDL cholesterol & 1.08 & $0.81-1.43$ & 1.10 & $0.80-1.50$ \\
\hline Elevated high-sensitivity CRP & 1.59 & $1.26-2.00$ & 1.78 & $1.34-2.33$ \\
\hline
\end{tabular}

Separate logistic regression models were calculated for every risk factor. OR was calculated for a 1-SD increase in the sum of skinfold thicknesses. All logistic regression models were adjusted for sex, physical activity level, alcohol consumption, smoking and family history of obesity. Significant $(P<0.05)$ values in bold.

Abbreviations: $O R$ odds ratio, $C l$ confidence interval, $B M I$ body mass index $H D L$ high density lipoprotein, $C R P$ C-reactive protein.
Epidemiological studies proved that overweight in childhood predicts the development of CVD in adulthood [26-28]. In our study, childhood BMI was associated with CVD risk factors such as obesity, metabolic syndrome, and hyperglycaemia. Although some authors questioned the causality of the association of CRP with metabolic disorders and related chronic diseases [29], we found that childhood BMI was associated with elevated level of high-sensitivity CRP in adults. Meanwhile, childhood BMI was not predictive of adult hypertension or dyslipidaemias. Our results are consistent with the findings reported by $\mathrm{Li} \mathrm{L}$ et al. who also established that childhood BMI was a weak predictor of adult hypertension and dyslipidaemias [6]. The pooled analysis of three British birth cohorts also showed that overweight in childhood and adolescence was associated with an increased risk of type 2 diabetes, while exposure to overweight in early life did not influence adult BP [15]. On the contrary, some longitudinal cohort studies found statistically significant associations of overweight in childhood with hypertension, high level of LDL cholesterol and triglycerides as well as low level of HDL cholesterol in adulthood [14].

Several studies examined the association between childhood BMI and metabolic syndrome in adults [30,31]. They reported that a rise in childhood BMI increased the odds of developing the metabolic syndrome. However, Lloyd LJ et al. found little evidence that childhood obesity is an independent risk factor for adult metabolic syndrome [32]. The authors argued that the associations might reflect the tracking of BMI because the majority of the studies did not adjust for adult BMI. In the present study, BMI gain was included into a logistic regression model; however, the adjustment did not diminish the effect of childhood BMI for the prediction of metabolic syndrome. 
Compared to BMI, skinfold thicknesses were more strongly associated with body fatness; therefore, it may be assumed that skinfold thicknesses would better predict CVD risk than BMI [33]. However, limited evidence exists on the effect of childhood skinfold thicknesses for the prediction of CVD risk in adults. In our study, the sum of subscapular and triceps skinfold thicknesses in childhood was associated with odds of obesity and central obesity, metabolic syndrome, hyperglycaemia or type 2 diabetes, and elevated high-sensitivity CRP in adulthood. Other researchers also found that CVD risk factors were related to both skinfold thicknesses and BMI; however, differences in the magnitude of these associations were small $[34,35]$. Freedman DS et al. demonstrated that BMI was at least as accurate as skinfold thicknesses in identifying metabolic risk in adults [35]. As compared to height and weight, a chance of errors is higher for skinfold thickness measurements; therefore, BMI is assumed to be more appropriate for assessment of weight status in childhood.

Our data demonstrated that not only childhood BMI, but also BMI gain from childhood were associated with adverse levels of cardiovascular risk factors in adulthood. Prospective studies carried out in UK and USA also found that BMI gain substantially increases CVD risk $[36,37]$. In adults of the same BMI, the risk of metabolic disorders differed depending on BMI gain from childhood to adulthood. Indeed, the individuals with persistent overweight from childhood to adulthood were at a higher cardiovascular risk compared to those with adultonset obesity $[14,15]$. On the contrary, the individuals whose adiposity decreased (relative to age and sex standards) had more favourable cardiovascular risk profiles $[14,37]$. These data emphasize that excessive weight gain should be prevented at any stage of life in order to reduce the risk of CVD.

The strength of the present study is the randomly selected cohort followed 35 years since childhood. All anthropometric measurements were carefully taken using standardized methodology in childhood and adulthood. A further strength includes the adjustment of odds of CVD risk factors for major life-style characteristics. The study has several limitations. During the 35-year followup, the loss of participants was quite substantial. A high rate of emigration from Lithuania over the last decades was one of the reasons for non-participation in the follow-up survey. Although no differences in baseline measurements were identified between participants and non-participants, the trends in BMI and CVD risk factors during the life course might be different in those groups. The loss to follow-up might have resulted in selection bias if non-response was associated with BMI gain and incidence of CVD risk factors. Our findings might not be generalized to Lithuanian population because baseline survey was carried out only in Kaunas city. However, a substantial proportion of cohort has spread all over the country during follow-up period. There is no reason to believe that the association between anthropometric measurements and CVD risk in our cohort is different from whole population. Finally, we were not able to adjust odds ratios for the changes in lifestyle factors due to lack of information about these factors in the baseline survey.

\section{Conclusions}

Childhood BMI was associated with risk of adult obesity, metabolic syndrome, hyperglycaemia or diabetes, and elevated high-sensitivity CRP, while risk of hypertension, raised triglycerides and reduced HDL cholesterol was predominantly affected by BMI gain from childhood to adulthood. The associations of the skinfold thicknesses with cardiovascular risk factors were similar to those of BMI. From a public health perspective, our study emphasizes the importance of primary prevention of overweight from early childhood with continuation of health promotion activities throughout the course of life.

\section{Abbreviations}

BMI: Body mass index; BP: Blood pressure; CHD: Coronary heart disease; CRP: C-reactive protein; CVD: Cardiovascular disease; HDL: High-density lipoproteins; IOTF: International Obesity Task Force; LDL: Low-density lipoproteins; OR: Odds ratio; SD: Standard deviation.

\section{Competing interests}

The authors declare that they have no competing interests.

\section{Authors' contributions}

JP made substantial contributions to conception and design of the manuscript, analyzed and made interpretation of the data, drafted the manuscript; JK made substantial contributions to the design of the study, revised the manuscript critically; VK participated in examination of participants, was involved in drafting of the manuscript; AR made interpretation of the data, was involved in drafting of the manuscript; ES analysed the data; IC participated in examination of participants, was involved in drafting of the manuscript. All authors read and approved the final manuscript.

\section{Acknowledgements}

The study was supported by a research grant from the Research Council of Lithuania for National Research Programme 'Chronic Noncommunicable Diseases' (LIG-01/2012).

\section{Author details}

${ }^{1}$ Faculty of Public Health, Medical Academy, Lithuanian University of Health Sciences, Siaures av. 57, Kaunas, Lithuania. 'Department of Cardiology, Medical Academy, Lithuanian University of Health Sciences, Eiveniu 2, Kaunas, Lithuania.

Received: 25 October 2014 Accepted: 12 February 2015 Published online: 04 March 2015

\section{References}

1. Ng M, Fleming T, Robinson M, Thomson B, Graetz N, Margono C, et al. Global, regional, and national prevalence of overweight and obesity in children and adults during 1980-2013: a systematic analysis for the Global Burden of Disease Study 2013. Lancet. 2014;384:766-81.

2. Currie C, Zanotti C, Morgan A, Currie D, de Looze M, Roberts C, et al. Social determinants of health and well-being among young people. Health Behaviour in School-aged Children (HBSC) study: international report from the 2009/2010 survey. Copenhagen: WHO Regional Office for Europe; 2012. 
3. Wijnhoven TM, van Raaij JM, Spinelli A, Rito Al, Hovengen R, Kunesova M, et al. WHO European Childhood Obesity Surveillance Initiative 2008: weight, height and body mass index in 6-9-year-old children. Pediatr Obes. 2013:8:79-97.

4. Field AE, Cook NR, Gillman MW. Weight status in childhood as a predictor of becoming overweight or hypertensive in early adulthood. Obes Res. 2005;13:163-9.

5. Singh AS, Mulder C, Twisk JW, van Mechelen W, Chipanaw MJ. Tracking of childhood overweight into adulthood: a systematic review of the literature. Obes Rev. 2008:9:474-88.

6. Li L, Pinot de Moira A, Power C. Predicting cardiovascular disease risk factors in mid-adulthood from childhood body mass index: utility of different cutoffs for childhood body mass index. Am J Clin Nutr. 2011:93:1204-11.

7. Juhola J, Magnussen CG, Viikari JS, Kähönen M, Hutri-Kähönen N, Jula A, et al. Tracking of serum lipid levels, blood pressure, and body mass index from childhood to adulthood: the Cardiovascular Risk in Young Finns Study. J Pediatr. 2011:159:584-90.

8. Guh DP, Zhang W, Bansback N, Amarsi Z, Birmingham CL. The incidence of co-morbidities related to obesity and overweight: a systematic review and meta-analysis. BMC Public Health. 2009;9:88.

9. Prospective Studies Collaboration, Whitlock $G$, Lewington S, Sherliker $P$ Clarke R, Emberson J, et al. Body-mass index and cause-specific mortality in 900000 adults: collaborative analyses of 57 prospective studies. Lancet. 2009;373:1083-96

10. Saydah S, Bullard KM, Cheng Y, Ali MK, Gregg EW, Geiss L, et al. Trends in cardiovascular disease risk factors by obesity level in adults in the United States, NHANES 1999-2010. Obesity (Silver Spring). 2014:22:1888-95.

11. Choi J, Joseph L, Pilote L. Obesity and C-reactive protein in various populations: a systematic review and meta-analysis. Obes Rev. 2013;14:232-44.

12. Owen CG, Whincup PH, Orfei L, Chou QA, Rudnicka AR, Wathern AK, et al. Is body mass index before middle age related to coronary heart disease risk in later life? Evidence from observational studies. Int J Obes (Lond). 2009;33:866-77.

13. Lloyd LJ, Langley-Evans SC, McMullen S. Childhood obesity and adult cardiovascular disease risk: a systematic review. Int J Obes (Lond) 2010;34:18-28.

14. Juonala M, Magnussen CG, Berenson GS, Venn A, Burns TL, Sabin MA, et al. Childhood adiposity, adult adiposity, and cardiovascular risk factors. N Engl J Med. 2011;365:1876-85.

15. Park MH, Sovio U, Viner RM, Hardy RJ, Kinra S. Overweight in childhood, adolescence and adulthood and cardiovascular risk in later life: pooled analysis of three British birth cohorts. PLoS One. 2013;8(7):e70684.

16. European Health for All Database (HFA-DB). [http://www.euro.who.int/hfadb]

17. Torok E, Caukas M, Gyarfas I. International collaborative study on juvenile hypertension. Budapest: Hungarian Institute of Cardiology; 1987.

18. Cole TJ, Bellizzi MC, Flegal KM, Dietz WH. Establishing a standard definition for child overweight and obesity worldwide: international survey. BMJ. 2000;320:1240-3

19. Alberti KG, Zimmet P, Shaw J. Metabolic syndrome-a new world-wide definition. A consensus statement from the international diabetes federation. Diabet Med. 2006;23:469-80.

20. Myers GL, Rifai N, Tracy RP, Roberts WL, Alexander RW, Biasucci LM, et al. CDC/AHA workshop on markers of inflammation and cardiovascular disease: application to Clinical and Public Health Practice: report from the laboratory science discussion group. Circulation. 2004;110:e545-9.

21. Craig $C L$, Marshall $A L$, Sjöström M, Bauman $A E$, Booth $M L$, Ainsworth $B E$, et al. International physical activity questionnaire: 12-country reliability and validity. Med Sci Sports Exerc. 2003;35:1381-95.

22. Grabauskas V, Klumbienè J, Petkeviciene J, Petrauskiene A, Tamosiunas A Kriaucioniene $V$, et al. Risk factors for non-communicable diseases in Lithuania rural population: CINDI survey 2007. Medicina (Kaunas). 2008:44:633-9.

23. Freedman DS, Khan LK, Serdula MK, Dietz WH, Srinivasan SR, Berenson GS. The relation of childhood BMI to adult adiposity: the Bogalusa Heart Study. Pediatrics. 2005;115:22-7

24. Engeland A, Bjorge T, Tverdal A, Sogaard AJ. Obesity in adolescence and adulthood and the risk of adult mortality. Epidemiology. 2004:15:79-85.

25. Guo SS, Wu W, Chumlea WC, Roche AF. Predicting overweight and obesity in adulthood from body mass index values in childhood and adolescence. Am J Clin Nutr. 2002;76:653-8.
26. Baker JL, Olsen LW, Sorensen TI. Childhood body-mass index and the risk of coronary heart disease in adulthood. N Engl J Med. 2007;357:2329-37.

27. Bjorge T, Engeland A, Tverdal A, Davey Smith G. Body mass index in adolescence in relation to cause-specific mortality: a follow-up of 230,000 Norwegian adolescents. Am J Epidemiol. 2008;168:30-7.

28. Reilly JJ, Kelly J. Long-term impact of overweight and obesity in childhood and adolescence on morbidity and premature mortality in adulthood: systematic review. Int J Obes (Lond). 2011;35:891-8.

29. Timpson NJ, Lawlor DA, Harbord RM, Gaunt TR, Day IN, Palmer LJ, et al. C-reactive protein and its role in metabolic syndrome: mendelian randomisation study. Lancet. 2005:366:1954-9.

30. Morrison JA, Friedman LA, Wang P, Glueck CJ. Metabolic syndrome in childhood predicts adult metabolic syndrome and type 2 diabetes mellitus 25 to 30 years later. J Pediatr. 2008;152:201-6.

31. Graversen L, Sorensen TI, Petersen L, Sovio U, Kaakinen M, Sandbaek A, et al. Preschool weight and body mass index in relation to central obesity and metabolic syndrome in adulthood. PLoS One. 2014;9(3):e89986.

32. Lloyd LJ, Langley-Evans SC, McMullen S. Childhood obesity and risk of the adult metabolic syndrome: a systematic review. Int J Obes (Lond). 2012;36:1-11.

33. Steinberger J, Jacobs DR, Raatz S, Moran A, Hong CP, Sinaiko AR. Comparison of body fatness measurements by BMI and skinfolds vs dual energy $X$-ray absorptiometry and their relation to cardiovascular risk factors in adolescents. Int J Obes (Lond). 2005;29:1346-52.

34. Birmingham B, Dyer AR, Shekelle RB, Stamler J. Subscapular and triceps skinfold thicknesses, body mass index and cardiovascular risk factors in a cohort of middle-aged employed men. J Clin Epidemiol. 1993;46:289-302.

35. Freedman DS, Katzmarzyk PT, Dietz WH, Srinivasan SR, Berenson GS. The relation of $\mathrm{BMI}$ and skinfold thicknesses to risk factors among young and middle-aged adults: the Bogalusa Heart Study. Ann Hum Biol. 2010;37:726-37

36. Attard SM, Herring AH, Howard AG, Gordon-Larsen P. Longitudinal trajectories of $\mathrm{BMI}$ and cardiovascular disease risk: the national longitudinal study of adolescent health. Obesity (Silver Spring). 2013;21:2180-8.

37. Pinto Pereira SM, Power C. Life course body mass index, birth weight and lipid levels in mid-adulthood: a nationwide birth cohort study. Eur Heart J. 2013;34:1215-24.

\section{Submit your next manuscript to BioMed Central and take full advantage of:}

- Convenient online submission

- Thorough peer review

- No space constraints or color figure charges

- Immediate publication on acceptance

- Inclusion in PubMed, CAS, Scopus and Google Scholar

- Research which is freely available for redistribution 